\title{
SPLICING ABNORMALITIES IN MYOTONIC DYSTROPHIES
}

\author{
DENIS FURLING $(*)$
}

RIASSUNTO. - La distrofia miotonica di tipo 1 (DM1) è tra le più comuni forme di distrofia muscolare nell'adulto, caratterizzata da progressivo deperimento e debolezza muscolare, miotonia, difetti di conduzione a livello cardiaco, alterate funzioni cognitive e da diversi altri sintomi multisistemici. La DM1 è una malattia ereditaria autosomica dominante, causata da un'instabile espansione ( $\mathrm{da} \sim 50$ a più di 1.000 ripetizioni) della tripletta nucleotidica CTG nella regione non-codificante all'estremità 3' del gene DMPK. L'espressione di RNA per DMPK contenenti l'espansione CUG supporta l'ipotesi di una effetto tossico dell'RNA per "acquisizione di funzione", come meccanismo alla base del fenotipo distrofico. Un meccanismo simile è pure coinvolto nella eziopatologia della distrofia miotonica di tipo 2 (DM2), che ha aspetti clinici comuni alla DM1 ed è causata dall'espansione della sequenza CCTG nel primo introne del gene CNP (ZNF9). In entrambe le distrofie miotoniche, l'accumulo a livello del nucleo cellulare di RNA contenenti le sequenze CUG/CCUG espanse altera l'attività di fattori proteici (quali MBNL1 e CUG-BP1) che legano gli RNA nucleari, con conseguente sregolazione dello splicing alternativo di numerosi trascritti nei tessuti dei pazienti DM ed insorgenza del fenotipo patologico. Verrà presentata una rassegna delle alterazioni di splicing nelle DM, con particolare riferimento all'mRNA del gene BIN1, che gioca un ruolo chiave nella formazione delle invaginazioni tubulari del sarcolemma, alla base della biogenesi dei tubuli $\mathrm{T}$ (strutture membranose essenziali, nel tessuto muscolare striato, per il corretto accoppiamento eccitazione/contrazione). Le alterazioni nello splicing di BIN1 nei pazienti affetti da DM, dovuto ad una perdita di funzione della proteina MBNL1, hanno come conseguenza l'espressione di un a forma inattiva della proteina BIN1, priva di attività di legame per i fosfoinositidi e della capacità di formare invaginazioni tubulari della membrana plasmatica. Introducendo in un modello murino normale un simile difetto di splicing per BIN1 si ottengono alterazioni dei tubuli $\mathrm{T}$ e diminuita forza muscolare: ciò suggerisce che l'alterazione dello splicing per questo gene possa direttamente determinare l'insorgenza di debolezza muscolare, una delle caratteristiche più significative delle DM.

(*) UPMC Univ Paris 6, UM 76, Institut de Myologie and Inserm, U974 and CNRS, UMR7215, 47/83 bld de l'hopital, F-75013, Paris, France.

E-mail : denis.furling@upmc.fr 
ABSTRACT. - Myotonic dystrophy of type 1 (DM1) is one of the most common muscular dystrophy in adults characterized by progressive muscle wasting and weakness, myotonia, cardiac conduction defects, alteration in cognitive functions as well as several other multisystemic symptoms. DM1 is an autosomal dominant inherited disease caused by an unstable CTG expansion ranging from $~ 50$ to more than 1,000 repeats in the 3' non-coding region of the DMPK gene. Expression of DMPK RNAs with expanded CUG repeats supports a toxic RNA gain-of-function as a pathologic mechanism for DM1. A similar or common mechanism may also be involved in DM type 2 that is caused by CCTG expansion in the first intron of the CNP (ZNF9) gene and shares similar clinical features with DM1 disease. In both myotonic dystrophies, nuclear accumulation of pathogenic CUG/CCUGexp-RNAs alters the activities of the RNA binding proteins such as MBNL1 and CUG-BP1 that leads to alternative splicing mis-regulation of a numerous of transcripts in DM tissues and ultimately, to clinical features of the disease. An overview of the DM splicing mis-regulation will be presented, with focus on mis- regulation of the BIN1 mRNA. In muscle, BIN1 plays an important role in tubular invaginations of the plasma membrane and is required for biogenesis of T-tubules, which are specialized membrane structures essential for excitation-contraction coupling. BIN1 splicing mis-regulation in DM patients due to MBNL1 loss-of-function results in the expression of an inactive form of BIN1 deprived of phosphoinositide-binding and membrane-tubulating activities. Reproducing similar BIN1 mis-splicing defect in the muscles of wild type mice is sufficient to promote T-tubule alterations and muscle strength decrease, suggesting that alteration of BIN1 splicing may contributes to muscle weakness, a prominent feature in DM.

KEY WORDS. - myotonic dystrophy, CTG repeats, RNA, alternative splicing, weakness.

\section{INTRODUCTION}

Myotonic dystrophy type 1 (DM1) also called Steinert disease (MIM\#160900) is one of the most common muscular dystrophies encountered in adults. Progressive muscle wasting and weakness, myotonia, cardiac conduction defects, alteration in cognitive functions as well as several other multisystemic symptoms characterize this dominantly inherited disease (Harper 2001). The DM1 mutation was identified in 1992 and this complex disease is caused by an expanding $(\mathrm{CTG}) \mathrm{n}$ repeat of 50 to several thousand triplets in the 3 'non-coding region of the dystrophia myotonica-protein kinase (DMPK) gene on chromosome 19 (Brook et al. 1992; Mahadevan et al. 1992). Unaffected individuals have fewer than 38 repeats. The size of the expansion is generally correlated with the clinical severity and the age of onset of the 
disease (Hunter et al. 1992; Tsilfidis et al. 1992; Groh et al. 2011). Due to the variable clinical symptoms, several forms of the disease (asymptomatic late-onset, mild adult-onset, childhood-onset and congenital) have been described. The severe congenital form is associated with large expansions (over 1500 CTG repeats), and affected patients have motor and mental retardation. The disease-associated repeat expansion is very unstable and the number of triplets increases across generations providing a molecular basis for the anticipation phenomenon observed in DM1 families (Harper et al. 1992; Lavedan et al. 1993). In addition to intergenerational instability, CTG repeat expansion is also unstable in somatic tissues throughout the lifetime of the patient.

Evidences for an RNA gain-of-function mechanism in DM1 pathogenesis came to light progressively. Both wild-type and mutant $D M P K$ alleles are transcribed into mRNAs but mutant transcripts with expanded CUG repeats (CUGexp-RNAs) are sequestered in the nucleus as discrete aggregates or foci leading to decrease cytoplasmic DMPK mRNA levels (Taneja et al. 1995; Davis et al. 1997). Subsequent reduction of DMPK protein levels has been a subject of controversy but reduced DMPK levels were observed in muscles samples from DM1 patients as well as DM1 muscle cells (Fu et al. 1992; Maeda et al. 1995; Furling et al. 2001; Furling et al. 2003). Possible involvement of DMPK haploinsufficiency in DM1 pathophysiology as well as reduced levels of SIX 5 observed in DM1 tissues due to the SIX homeobox 5 (SIX5) gene location directly downstream from the DM1 locus, were first investigated by generating mouse models. However heterozygous Dmpk or Six 5 knockout mice failed to reproduce DM1-like symptoms suggesting that DMPK or SIX5 haploinsufficiency are probably not responsible for the DM1 phenotype (Jansen et al. 1996; Reddy et al. 1996; Klesert et al. 2000; Sarkar et al. 2000). Afterwards it has been suggested that the mutant transcripts from the expanded DMPK allele were pathogenic per se. Animal models were developed to investigate the role and the deleterious effects of CUGexp-RNA expression. Transgenic mice that expressed CUG repeat expansion either in the 3'UTR of the human skeletal muscle alpha actin (HSA-LR) mRNA (Mankodi et al. 2000) or in its natural context within the 3'UTR of the human DMPK transcript (Seznec et al. 2001), exhibited several DM1 features including nuclear aggregates of CUGexp-RNA, myotonia discharges and muscle abnormalities. In addition, severe muscle wasting was described in an inducible EpA960/HSA-Cre-ER transge- 
nic mice expressing 960 interrupted CTG repeats within the context of the DMPK exon 15 (Orengo et al. 2008) and progressive muscle atrophy was observed in mice expressing human DMPK mRNA with 550 CUG repeats (Vignaud et al. 2010). Altogether, these studies provided strong experimental supports for a key role of CUGexp-RNAs in DM1 pathogenesis. The last evidence for a RNA gain-of-function mechanism came from the identification of a myotonic dystrophy type 2 disorder (DM2; MIM\#602668) that shares similar clinical features with DM1 disease suggesting a common molecular mechanism. DM2 is caused by a (CCTG)n repeat expansion ranging from 100 to 11.000 units in the first intron of the CCHC-type zinc finger, nucleic acid binding protein (CNBP also known as ZNF9) gene, a non-coding region from a gene non-related to DMPK (Liquori et al. 2001). The RNAs containing the expanded CCUG repeats are also retained in the nucleus and formed aggregates providing an additional support for a central role of mutant RNAs containing expanded repeats in pathophysiology of both DM1 and DM2 diseases.

The CUGexp-RNAs are not exported into the cytoplasm but are retained in the nuclear compartment as discrete aggregates or foci that are easily detected by FISH (Taneja et al. 1995). The mutant DMPK mRNAs are spliced and polyadenylated but their nuclear sequestration due to expanded CUG repeats in the 3'UTR, prevents any translation (Davis et al. 1997). Within the nuclei, the foci of CUGexp-RNAs are localized at the periphery of the nuclear speckles, which are structures enriched in splicing snRNPs and the spliceosome assembly factor SC35 as well as many other transcription and splicing-related factors (Holt $e t$ al. 2007). The pathogenic DMPK transcripts do not enter into the speckles (Smith et al. 2007) suggesting that their export is blocked at an early step in nucleoplasmic transport. In vitro studies including crystal structure, enzymatic mapping, optical melting and electron microscopy, have demonstrated that expanded CUG repeats are able to form stable hairpin structures (Michalowski et al. 1999; Miller et al. 2000; Tian et al. 2000; Mooers et al. 2005).

These double-stranded structures are defined by Watson-Crick G-C base-pairs separated by a periodic U-U mismatch. The muscleblind-like 1 (MBNL1) proteins were found to bind these expanded CUG repeats and to colocalize with nuclear foci of CUGexp-RNAs in DM1 cells (Miller et al. 2000). MBNL1 silencing by RNA interference significantly reduces the number of foci and restores the capacity of 
these pathogenic transcripts to progress through the nuclear speckles (Smith et al. 2007) indicating that the binding of MBNL1 to the abnormal CUG repeats may promote nuclear foci formation (Miller et al. 2000; Dansithong et al. 2005; Smith et al. 2007). It should be noted that MBNL1 also colocalizes with the nuclear foci of CCUG expanded RNA in DM2 cells however the DM2 foci are not localized at the periphery of the nuclear speckles as observed for the DM1 foci (Holt et al. 2007). Besides the difference within the expanded nucleotide repeat (CUG vs. CCUG) between DM1 and DM2, the entrapped RNAs in DM2 may contain intronic expanded CCUG repeats only since the CNBP pre-mRNA seems to be normally spliced (Margolis et al. 2006) and/or expanded CCUG repeats into abnormally spliced CNBP transcripts (Raheem et al. 2010). Finally, nuclear retention of the CUGexpRNAs participates to the pathogenic mechanism since the nuclear export of an artificial CUGexp-RNAs by inclusion of woodchuck posttranscriptional regulatory element reduces cellular defects (Mastroyiannopoulos et al. 2005) and the expression of DM1 foci exclusively in the cytoplasmic compartment does not induce key DM1 features in a mouse model (Dansithong et al. 2008).

At the molecular level, one of the best-characterized transdominant effects induced by the CUGexp-RNAs in DM1 is the misregulation of alternative splicing of a subset of pre- mRNAs. To date, more than twenty-five transcripts have been found to be mis-spliced in different tissues of DM1 patients (Osborne and Thornton 2006). The misregulation of splicing events in DM1 is distinct from aberrant splicing caused by mutations in regulatory splicing sites that lead to the expression of aberrant mRNA. In DM1, mis-splicing events result from an inappropriate regulation of alternative splicing due to altered activities of splicing regulators such as MBNL1 and CELF1:

- the MBNL1 RNA binding protein has been shown to bind, in a length-dependant manner, CUGexp-RNA with high affinity and form ribonucleoprotein complexes (Miller et al. 2000). MBNL1 is part of a conserved MBNL family including MBNL1, 2, 3, and all members contain four $\mathrm{CCCH}$ zinc-finger protein domains that are structured in pairs and acted as RNA binding domains (Pascual et al. 2006). Sequestration of MBNL1 within the nuclear aggregates of CUGexp-RNAs and the subsequent involvement of MBNL1 lossof-function in DM1 pathogenesis has been supported by the generation of a knockout Mbnl1 mouse model that demonstrates a DM- 
like phenotype as well as alternative splicing misregulation (Kanadia et al. 2003). Moreover a majority of the modifications in alterative splicing observed in the HSA-LR mice expressing CUGexp-RNA can be attributed to the loss-of-function of the MBNL1 splicing factor (Osborne et al. 2009; Du et al. 2010). In addition, mis-splicing events observed in this DM1 mouse model as well as myotonia can be reversed by MBNL1 overexpression in skeletal muscles (Kanadia et al. 2006). Several reports have demonstrated the regulatory splicing function of MBNL1 on several DM1 transcripts such as CLC1, cTNT or IR. Now, it is established that MBNL1 loss-of-function due to its sequestration by the CUGexp-RNA contributes to the "spliceopathy" in DM1.

- CELF1 (also known as CUGBP1) is another RNA binding protein involved in this process. This factor is a member of the CELF family that contains 6 proteins with high homology (Barreau et al. 2006). Interestingly, CELF1 and MBNL1 are antagonistic regulators of many splicing events that are mis-regulated in DM1. CELF1 is able to bind single-strand CUG repeats but does not colocalize with the nuclear aggregates of CUGexp-RNA in DM1 cells and is not sequestered like MBNL1 (Timchenko et al. 2001). In contrast, the level of CELF1 is increased in DM1 tissues leading to a gain of CELF1 activity. It has been shown that the expression of CUGexp-RNA results in hyperphosphorylation and stabilization of the CELF1 protein through an inappropriate activation of the Protein Kinase $\mathrm{C}$ (Kuyumcu-Martinez et al. 2007; Wang et al. 2009). The pathogenic role of CELF1 in DM1 was supported by the fact that transgenic mice overexpressing CELF1 reproduce splicing misregulation as well as DM1 muscle features (Koshelev et al. 2010; Ward et al. 2010). Furthermore, increased levels of CELF1 is also found in the DM1 mouse model expressing inducible 960 interrupted CTG repeats, which exhibits muscle wasting as well as splicing defects that are only related to CELF1 (e.g. Capzb, Mfn2, Ank2 and Fxr1b) and not to MBNL1, suggesting that the elevation of CELF1 could participate to the DM1 muscle phenotype (Orengo et al. 2008).

MBNL1 and CELF1 factors are developmental regulators of splicing events especially during the fetal to adult transition, and the modification of their activities in DM1 tissues leads to the expression of a fetal splicing pattern in adult tissues (Lin et al. 2006; Kalsotra et al. 2008). It should be noted that altered expression of splicing factors and 
alternative splicing changes may also occur during active regeneration process in degenerative muscle diseases (Orengo et al.). However no massive degeneration/regeneration was observed in DM1 muscles (Thornell et al. 2009) and altered splicing events were found in nonregenerating tissue such as DM1 cardiac tissue (Philips et al. 1998; Wang et al. 2011) confirming that misregulation of alternative splicing in DM1 is more likely a primary response to the expression of CUGexp-RNAs rather than a secondary effect to robust degeneration/regeneration process. The first splicing misregulation described in DM1 cardiac muscle was the abnormal inclusion of exon 5 in cTNT (Philips et al. 1998). Since then, several other transcripts with inappropriate splicing patterns have been identified in both skeletal muscle and brain (see Table 1) including those coding for the insulin receptor (IR) (Savkur et al. 2001), the muscle specific chloride channel (CLC1)(Charlet et al. 2002; Mankodi et al. 2002), the sarcoplasmic/endoplasmic reticulum $\mathrm{Ca}^{2+}$ ATPase 1 and 2, the ryanodine receptor (Kimura et al. 2005), the myotubularine-related protein 1(Buj-Bello et al. 2002), the tau protein (Sergeant et al. 2001), and the N-methyl-alpha-aspartate receptor (Jiang et al. 2004). Among the known mis-splicing events, most of them may participate to the pathologic process but very few have been directly correlated with disease symptoms. One of the exceptions is the CLC-1 splicing defect, which has been associated with myotonia, a characteristic feature of the disease. This splicing misregulation leads to the inclusion of exon $7 \mathrm{a}$ and subsequently to a truncated CLC1 protein that is devoid of channel activity and is not correctly addressed to the membrane of the muscle fibers, resulting in reduced muscle chloride conductance and myotonia (Charlet et al. 2002; Mankodi et al. 2002). Consistent with the RNA gain-of-function hypothesis that altered MBNL1 activity, both MBNL1 knockout mice and HSA-LR mice that express CUGexp-RNA showed Clc-1 splicing misregulation, loss of $\mathrm{Clc}-1$ channel at the membrane, and myotonia. Finally, correction of this sole splicing defect by using antisense oligonucleotide that force the skipping of exon $7 \mathrm{a}$ in the muscle of HSA-LR mice abolished myotonia (Wheeler et al. 2007) confirming the key role of Clc-1 mis-splicing in the myotonic phenotype in DM1.

More recently, the newly identified BIN1 splicing defect has been associated with muscle weakness, another hallmark of DM1 (Fugier et al. 2011). This splicing defect was identified in collaboration with $\mathrm{N}$. Charlet by using a whole genome approach (Affymetrix exon array). 
Table 1.

\begin{tabular}{|c|c|c|c|c|}
\hline Tisues & Pre-mRNA & $\begin{array}{l}\text { Exon/intron } \\
\text { deregulation }\end{array}$ & $\begin{array}{l}\text { Inclusion/ } \\
\text { exclusion }\end{array}$ & Ref. \\
\hline Skeletal & Insulin receptor (INSR) & Exon 11 & Exclusion & Savkur et al., 2001 \\
\hline \multirow[t]{22}{*}{ Muscle } & \multirow[t]{2}{*}{ Chloride channel (CLCN1) } & Intron 2 & Inclusion & $\begin{array}{l}\text { Charlet et al., } 2002 \\
\text { Mankodi et al., } 2002\end{array}$ \\
\hline & & Exon 7A & Inclusion & Lueck et al., 2006 \\
\hline & BIN1 (Amphyphisine 2) & Exon 11 & Exclusion & Fugier et al., 2011 \\
\hline & Calcium channel $(\mathrm{Ca}(\mathrm{V}) 1.1)$ & Exon 29 & Exclusion & Tang et al., 2012 \\
\hline & Skeletal Troponin T (TNNT3) & Exon fœtal & Inclusion & Kanadia et al., 2003 \\
\hline & Ryanodine recptor (RyR1) & Exon 70 & Exclusion & Kimura et al., 2005 \\
\hline & $\begin{array}{l}\text { Sarcoplasmic/endoplasmic } \\
\text { reticulum Ca2+ ATPase1 } \\
\text { (SERCA1) }\end{array}$ & Exon 22 & Exclusion & \\
\hline & $\begin{array}{l}\text { Sarcoplasmic/endoplasmic } \\
\text { réticulum Ca2+ ATPase2 } \\
\text { (SERCA2) }\end{array}$ & Intron 19 & Inclusion & \\
\hline & $\begin{array}{l}\text { LIM domain inding } 3 \\
\text { (LB, ZASP) }\end{array}$ & 11 & Inclusion & Lin et al., 2006 \\
\hline & \multirow[t]{2}{*}{ Titin (TTN) } & $\mathrm{Zr} 4$ & Inclusion & \\
\hline & & $\mathrm{Zr} 5$ & Inclusion & \\
\hline & $\begin{array}{l}\text { Nebulin-related anchoring } \\
\text { protein (NRAP) }\end{array}$ & 12 & Inclusion & \\
\hline & Calpaïn 3 (CAPN3) & 16 & Exclusion & \\
\hline & Attractin-like (ATRNL1, ALP) & $5 a$ et $5 b$ & Inclusion & \\
\hline & $\begin{array}{l}\text { Forming homology } 2 \text { domain } \\
\text { containing } 1 \text { (FHOD1) }\end{array}$ & $11 \mathrm{a}$ & Exclusion & \\
\hline & $\begin{array}{l}\text { Glutamine-fructose-6-phosphate } \\
\text { transaminase } 1 \text { (GFPT1) }\end{array}$ & 10 & Exclusion & \\
\hline & MBNL1 & 7 & Inclusion & \\
\hline & MBNL2 & 7 & Inclusion & \\
\hline & $\begin{array}{l}\text { SET and MYND domain } \\
\text { containing } 1 \text { (SMYD1) }\end{array}$ & 39 & Inclusion & Du et al., 2010 \\
\hline & Sperm associated antigen 9 & 39 & Inclusion & \\
\hline & \multirow{2}{*}{$\begin{array}{l}\text { Myotubularin-related protein } 1 \\
\text { (MTMR1) }\end{array}$} & Exon 2.1 & Exclusion & Buj-Bello et al., 2002 \\
\hline & & Exon2.3 & Exclusion & Ho et al., 2005 \\
\hline & \multirow[t]{2}{*}{ Alpha-dystrobrevin (DTNA) } & Exon 11a & Inclusion & Nakamori et al., 2008 \\
\hline & & Exon 12 & Inclusion & \\
\hline \multirow[t]{8}{*}{ Brain } & \multirow[t]{5}{*}{ Tau (MAPT) } & Exon 2 & Exclusion & Sergean et al., 2001 \\
\hline & & Exon 3 & Exclusion & \\
\hline & & $\overline{\text { Exon } 6}$ & $\begin{array}{l}\text { Exclusion } \\
\text { exon } 6 c\end{array}$ & Leroy et al., 2006 \\
\hline & & & $\begin{array}{l}\text { Inclusion } \\
\text { exon } 6 \mathrm{~d}\end{array}$ & \\
\hline & & Exon 10 & Exclusion & $\begin{array}{l}\text { Sergeant et al., } 2001 \\
\text { Jiang et al., } 2004\end{array}$ \\
\hline & $\begin{array}{l}\text { Récepteur-N-methyl-D- } \\
\text { aspartate (NMDAR1) }\end{array}$ & Exon 5 & Inclusion & Jiang et al., 2004 \\
\hline & Amyloid precursor protein (APP) & Exon 7 & Exclusion & \\
\hline & MBNL1 & Exon 5 & Inclusion & Dhaenens et al., 2010 \\
\hline
\end{tabular}


New as well as previously described splicing alteration events were identified in congenital DM1 muscle cells containing large CTG expansion and confirmed in skeletal muscles from DM patients. We focus our attention on BIN1 exon 11 splicing misregulation since mutation in this gene leads to Centronuclear Myopathy that share some similar features with the severe congenital form of DM1. BIN1 is a protein specialized in membrane curvature, whose function is regulated by alternative splicing. In skeletal muscles, inclusion of the muscle-specific exon 11, which encodes a phosphoinositide-binding (PI) domain, generates an isoform of BIN1 that induces tubular invaginations of membranes and is implicated in T- tubules biogenesis. The muscle T-tubule network is a specialized membrane structure fundamental for excitation-contraction (E-C) coupling, and the disruption of BIN1 in Drosophila leads to severely disorganized T-tubules and defects of the E-C coupling machinery. We demonstrate that MBNL1 binds to BIN1 pre-mRNA and regulates its alternative splicing. BIN1 splicing misregulation results in expression of an inactive form of BIN1 deprived of PtdIns5P-binding and membrane-tubulating activities. Consistent with a defect of BIN1, muscle T-tubules are altered in DM patients and membrane structures are restored upon expression of the normal splicing form of BIN1 in DM1 muscle cells. In non- affected muscles, BIN1 is organized in transversal projections and co-localized with the L- type calcium channel CACNA1S. In DM1 muscles, BIN1 was disorganized and presented a more diffuse localization. Ultrastructural analysis confirmed alterations of the T-tubule network with presence of irregular and longitudinally orientated T-tubules. To test the contribution of BIN1 splicing alteration for DM phenotype, we artificially forced exon 11 skipping in mouse skeletal muscle using an U7-snRNA exon-skipping strategy. Artificial skipping of Bin1 exon 11 promotes Bin1 mis-localization but no major atrophy or degeneration of muscle fibers. However $\sim 30 \%$ of T-tubules were abnormal in Bin 1 exon 11 skipped muscles, with longitudinally orientated, disorganized and irregular structures suggesting that alteration of the T-tubule network. No significant muscle mass loss was observed but isometric strength measurement showed that skipping of Bin1 exon 11 induced a $28 \%$ decreased of specific muscle strength. Our results suggest that splicing mis-regulation of BIN1 and of other pre-mRNAs involved in E-C coupling ultimately results in muscle weakness in DM patients. Interestingly, a recent report (Tang et al. 2012) proposed that mis-spli- 
cing of the Cac1.1 that altered the function of this calcium channel is also associated with muscle weakness and may exacerbate DM1 myopathy. Altogether, these data suggest that a common mechanism, involving BIN1 and alteration of the calcium homeostasis coupled to the excitation-contraction process, may underlie muscle weakness in DM1.

Over the years, the RNA gain-of-function hypothesis has progressively emerged as a pathogenic mechanism for the complex DM1 disease. Alternative splicing misregulation of several pre-mRNAs due to the altered activities of MBNL1 and CELF1 RNA binding proteins by CUGexp-RNAs, contributes to the DM1 pathophysiology. However it seems unlike that it can explain the wide spectrum of DM1 clinical symptoms. The CUGexp-RNAs have effects in trans and may alter other processes at both transcriptional and post-transcriptional levels. Indeed, altered activities of the MBNL1 and CELF1 may affect other RNA-processing events regulated by these RNA binding proteins. Thus, the activity of CELF1 varies depending on its cellular localization. In the nucleus, CELF1 acts as a splicing regulator whereas in the cytoplasm, it can regulate the translational activity of proteins like p21 and MEF2A, which are involved in muscle cell differentiation (Iakova et al. 2004; Timchenko et al. 2004). A concomitant translational deregulation of CELF1 targets and associated functions indicate that other post-transcriptional mechanisms could also be altered by the CUGexpRNAs. Unlike CELF1, no effect on translation has been described for MBNL1 yet, even though MBNL1 is also present in the cytoplasmic compartment. Alternative splicing results in the production of several isoforms of MBNL1 and the associated protein isoforms have been shown to have either a nuclear or a nucleo-cytoplasmic localization (Tran et al. 2011). It should be noted that the splicing of MBNL1 itself is altered in DM1 leading to increased levels of exclusively the nuclear isoforms. However the impact of such alterations on the activities of MBNL1 is still not clearly understood. More recently, a novel function of MBNL1 as a regulator of the micro-RNA miR-1 biogenesis has been described (Rau et al. 2011). Consistent with MBNL1 sequestration and loss-of-function, miR-1 processing was altered in the hearts of DM1 patients as well as miR-1 targets such as CACNA1 and GJA1 that encode calcium and gap junction channels, respectively. Interestingly, other 
micro-RNAs were also deregulated in muscles of DM1 patients suggesting that the deregulation of this species of small non-coding RNA could have an impact on DM1 pathology (Gambardella et al. 2010; Perbellini et al. 2011). Finally, there is increasing evidence (Yadava et al. 2008; Osborne et al. 2009; Du et al. 2010; Marteyn et al. 2011) to suggest that the CUGexp-RNAs may also interfere with gene expression but further studies are required to determine the mechanism involved in this process and the pathophysiological consequences. By interfering with RNA metabolism of either coding or non-coding RNAs, the CUGexp-RNAs may act on the expression of various proteins in a tissue-specific manner and participate to the complex and multisystemic DM1 phenotype.

\section{ACKNOWLEDGMENTS}

The author would like to thank the Association Française contre les Myopathies (AFM), UPMC, Inserm and CNRS. 


\section{REFERENCES}

Barreau C., L. Paillard, et al. (2006). Mammalian CELF/Bruno-like RNA-binding proteins: molecular characteristics and biological functions. Biochimie 88(5): 515-25.

Brook J.D., M.E. McCurrach, et al. (1992). Molecular basis of myotonic dystrophy: expansion of a trinucleotide (CTG) repeat at the 3' end of a transcript encoding a protein kinase family member. Cell 68: 799-808.

Buj-Bello,A., D. Furling, et al. (2002). Muscle-specific alternative splicing of myotubularinrelated 1 gene is impaired in DM1 muscle cells. Hum Mol Genet 11(19): 2297-307.

Charlet B.N., R.S. Savkur, et al. (2002). Loss of the muscle-specific chloride channel in type 1 myotonic dystrophy due to misregulated alternative splicing. Mol Cell 10(1): 45-53.

Dansithong W., S. Paul, et al. (2005). MBNL1 is the primary determinant of focus formation and aberrant insulin receptor splicing in DM1. J Biol Chem 280(7): 5773-80.

Dansithong W., C.M. Wolf, et al. (2008). Cytoplasmic CUG RNA foci are insufficient to elicit key DM1 features. PLoS One 3(12): e3968.

Davis B.M., M.E. McCurrach, et al. (1997). Expansion of a CUG trinucleotide repeat in the 3' untranslated region of myotonic dystrophy protein kinase transcripts results in nuclear retention of transcripts. Proc Natl Acad Sci U S A 94(14): 7388-93.

Du H., M.S. Cline, et al. (2010). Aberrant alternative splicing and extracellular matrix gene expression in mouse models of myotonic dystrophy. Nat Struct Mol Biol 17(2): 187-93.

Fu Y.-H., A. Pizzuti, et al. (1992). An unstable triplet repeat in a gene related to myotonic muscular dystrophy. Science 255: 1256-1258.

Fugier C., A.F. Klein, et al. (2011). Misregulated alternative splicing of BIN1 is associated with $T$ tubule alterations and muscle weakness in myotonic dystrophy. Nat Med 17(6): 720-5. Furling, D., L. Coiffier, et al. (2001). Defective satellite cells in congenital myotonic dystrophy. Hum Mol Genet 10(19): 2079-87.

Furling D., T. Lam le, et al. (2003). Changes in myotonic dystrophy protein kinase levels and muscle development in congenital myotonic dystrophy. Am J Pathol 162(3): 1001-9.

Gambardella S., F. Rinaldi, et al. (2010). Overexpression of microRNA-206 in the skeletal muscle from myotonic dystrophy type 1 patients. J Transl Med 8: 48.

Groh W.J., M.R. Groh, et al. (2011). Survival and CTG repeat expansion in adults with myotonic dystrophy type 1. Muscle Nerve 43(5): 648-51.

Harper P.S. (2001). The genetic basis of myotonic dystrophy. Myotonic Dystrophy. W. Saunders. London: 307-363.

Harper P.S., H.G. Harley, et al. (1992). Anticipation in myotonic dystrophy: new light on an old problem. Am J Hum Genet 51(1): 10-6. 
Holt I., S. Mittal, et al. (2007). Defective mRNA in myotonic dystropby accumulates at the periphery of nuclear splicing speckles. Genes Cells 12(9): 1035-48.

Hunter A., C. Tsilfidis, et al. (1992). The correlation of age of onset with CTG trinucleotide repeat amplification in myotonic dystrophy. J Med Genet 29(11): 774-9.

Iakova P., G.L. Wang, et al. (2004). Competition of CUGBP1 and calreticulin for the regulation of p21 translation determines cell fate. Embo J 23(2): 406-17.

Jansen G., P.J. Groenen, et al. (1996). Abnormal myotonic dystrophy protein kinase levels produce only mild myopathy in mice. Nat Genet 13(3): 316-24.

Jiang H., A. Mankodi, et al. (2004). Myotonic dystrophy type 1 is associated with nuclear foci of mutant RNA, sequestration of muscleblind proteins and deregulated alternative splicing in neurons. Hum Mol Genet 13(24): 3079-88.

Kalsotra A., X. Xiao, et al. (2008). A postnatal switch of CELF and MBNL proteins reprograms alternative splicing in the developing heart. Proc Natl Acad Sci U S A 105(51): 20333-8.

Kanadia R.N., K.A. Johnstone, et al. (2003). A muscleblind knockout model for myotonic dystrophy. Science 302(5652): 1978-80.

Kanadia R.N., J. Shin, et al. (2006). Reversal of RNA missplicing and myotonia after muscleblind overexpression in a mouse poly(CUG) model for myotonic dystrophy. Proc Natl Acad Sci U S A 103(31): 11748-53.

Kimur T., M. Nakamori, et al. (2005). Altered mRNA splicing of the skeletal muscle ryanodine receptor and sarcoplasmic/endoplasmic reticulum Ca2+-ATPase in myotonic dystrophy type 1. Hum Mol Genet 14(15): 2189-200.

Klesert T.R., D.H. Cho, et al. (2000). Mice deficient in Six 5 develop cataracts: implications for myotonic dystrophy. Nat Genet 25(1): 105-9.

Koshelev M., S. Sarma, et al. (2010). Heart-specific overexpression of CUGBP1 reproduces functional and molecular abnormalities of myotonic dystropby type 1. Hum Mol Genet 19(6): 1066-75.

Kuyumcu-Martinez N.M., G.S. Wang, et al. (2007). Increased steady-state levels of CUGBP1 in myotonic dystrophy 1 are due to PKC-mediated byperphosphorylation. Mol Cell 28(1): 68-78.

Lavedan C., H. Hofmann-Radvanyi, et al. (1993). Myotonic dystrophy: size- and sexdependent dynamics of CTG meiotic instability, and somatic mosaicism. Am J Hum Genet 52(5): 875-83.

Lin X., J.W. Miller, et al. (2006). Failure of MBNL1-dependent post-natal splicing transitions in myotonic dystrophy. Hum Mol Genet 15(13): 2087-97.

Liquori C.L., K. Ricker, et al. (2001). Myotonic dystropby type 2 caused by a CCTG expansion in intron 1 of ZNF9. Science 293(5531): 864-7.

Maeda M., C.S. Taft, et al. (1995). Identification, tissue-specific expression, and subcellular localization of the 80- and 71-kDa forms of myotonic dystrophy kinase protein. J Biol Chem 270(35): 20246-9.

Mahadevan M., C. Tsilfidis, et al. (1992). Myotonic dystrophy mutation: an unstable CTG repeat in the 3' untranslated region of the gene. Science 255(5049): 1253-5.

Mankodi A., E. Logigian, et al. (2000). Myotonic dystrophy in transgenic mice expressing an expanded CUG repeat. Science 289(5485): 1769-73. 
Mankodi A., M.P. Takahashi, et al. (2002). Expanded CUG repeats trigger aberrant splicing of ClC-1 chloride channel pre-mRNA and byperexcitability of skeletal muscle in myotonic dystrophy. Mol Cell 10(1): 35-44.

Margolis J.M., B.G. Schoser, et al. (2006). DM2 intronic expansions: evidence for CCUG accumulation without flanking sequence or effects on ZNF9 $m R N A$ processing or protein expression. Hum Mol Genet 15(11): 1808-15.

Marteyn A., Y. Maury, et al. (2011). Mutant buman embryonic stem cells reveal neurite and synapse formation defects in type 1 myotonic dystrophy. Cell Stem Cell 8(4): 434-44.

Mastroyiannopoulos N.P., M.L. Feldman, et al. (2005). Woodchuck post-transcriptional element induces nuclear export of myotonic dystrophy 3' untranslated region transcripts. EMBO Rep 6(5): 458-63.

Michalowski S., J.W. Miller, et al. (1999). Visualization of double-stranded RNAs from the myotonic dystrophy protein kinase gene and interactions with CUG-binding protein. Nucleic Acids Res 27(17): 3534-42.

Miller J.W., C.R. Urbinati, et al. (2000). Recruitment of human muscleblind proteins to (CUG) (n) expansions associated with myotonic dystrophy. Embo J 19(17): 4439-48.

Mooers B.H., J.S. Logue, et al. (2005). The structural basis of myotonic dystrophy from the crystal structure of CUG repeats. Proc Natl Acad Sci U S A 102(46): 16626-31.

Orengo J.P., P. Chambon, et al. (2008). Expanded CTG repeats within the DMPK 3' UTR causes severe skeletal muscle wasting in an inducible mouse model for myotonic dystrophy. Proc Natl Acad Sci U S A 105(7): 2646-51.

Orengo J.P., A.J. Ward, et al. (2011). Alternative splicing dysregulation secondary to skeletal muscle regeneration. Ann Neurol 69(4): 681-90.

Osborne R.J., X. Lin, et al. (2009). Transcriptional and post-transcriptional impact of toxic RNA in myotonic dystrophy. Hum Mol Genet 18(8): 1471-81.

Osborne R.J. and C.A. Thornton (2006). RNA-dominant diseases. Hum Mol Genet 15 Suppl 2: R162-9.

Pascual M., M. Vicente, et al. (2006). The Muscleblind family of proteins: an emerging class of regulators of developmentally programmed alternative splicing. Differentiation 74(2-3): 65-80.

Perbellini R., S. Greco, et al. (2011). Dysregulation and cellular mislocalization of specific miRNAs in myotonic dystrophy type 1. Neuromuscul Disord 21(2): 81-8.

Philips A.V., L.T. Timchenko, et al. (1998). Disruption of splicing regulated by a CUGbinding protein in myotonic dystrophy. Science 280(5364): 737-41.

Raheem O., S.E. Olufemi, et al. (2010). Mutant (CCTG)n expansion causes abnormal expression of zinc finger protein 9 (ZNF9) in myotonic dystrophy type 2. Am J Pathol 177(6): 3025-36.

Rau F., F. Freyermuth, et al. (2011). Antagonistic role of MBNL1 and LIN28 promotes specific alteration of pre-miR-1 processing and is associated with heart defects in Myotonic Dystrophic Patients. Nature structural and molecular biology in press.

Reddy S., D.B. Smith, et al. (1996). Mice lacking the myotonic dystrophy protein kinase develop a late onset progressive myopathy. Nat Genet 13(3): 325-35.

Sarkar P.S., B. Appukuttan, et al. (2000). Heterozygous loss of Six5 in mice is sufficient to cause ocular cataracts. Nat Genet 25(1): 110-4. 
Savkur R.S., A.V. Philips, et al. (2001). Aberrant regulation of insulin receptor alternative splicing is associated with insulin resistance in myotonic dystrophy." Nat Genet 29(1): 40-7.

Sergeant N., B. Sablonniere, et al. (2001). Dysregulation of human brain microtubuleassociated tau mRNA maturation in myotonic dystrophy type 1. Hum Mol Genet 10(19): 2143-55.

Seznec H., O. Agbulut, et al. (2001). Mice transgenic for the buman myotonic dystrophy region with expanded CTG repeats display muscular and brain abnormalities. Hum Mol Genet 10(23): 2717-26.

Smith K.P., M. Byron, et al. (2007). Defining early steps in mRNA transport: mutant $m R N A$ in myotonic dystrophy type I is blocked at entry into SC-35 domains. J Cell Biol 178(6): 951-64.

Taneja K.L., M. McCurrach, et al. (1995). Foci of trinucleotide repeat transcripts in nuclei of myotonic dystrophy cells and tissues. J Cell Biol 128(6): 995-1002.

Tang Z.Z., V. Yarotskyy, et al. (2012). Muscle weakness in myotonic dystrophy associated with misregulated splicing and altered gating of $\mathrm{Ca}(V) 1.1$ calcium channel. Hum Mol Genet 21(6): 1312-24.

Thornell L.E., M. Lindstom, et al. (2009). Satellite cell dysfunction contributes to the progressive muscle atrophy in myotonic dystrophy type 1. Neuropathol Appl Neurobiol 35(6): 603-13.

Tian B., R.J. White, et al. (2000). Expanded CUG repeat RNAs form hairpins that activate the double-stranded RNA-dependent protein kinase PKR. Rna 6(1): 79-87.

Timchenko N.A., Z.J. Cai, et al. (2001). RNA CUG repeats sequester CUGBP1 and alter protein levels and activity of CUGBP1. J Biol Chem 276(11): 7820-6.

Timchenko N.A., R. Patel, et al. (2004). Overexpression of CUG triplet repeat binding protein, CUGBP1, in mice inbibits myogenesis. J Biol Chem 279: 13129-39.

Tran H., N. Gourrier, et al. (2011). Analysis of exonic-regions involved in nuclear localization, splicing activity and dimerization of muscleblind-like-1 isoforms. J Biol Chem.

Tsilfidis C., A.E. MacKenzie, et al. (1992). Correlation between CTG trinucleotide repeat length and frequency of severe congenital myotonic dystrophy. Nat Genet 1(3): 192-5.

Vignaud A., A. Ferry, et al. (2010). Progressive skeletal muscle weakness in transgenic mice expressing CTG expansions is associated with the activation of the ubiquitinproteasome pathway. Neuromuscul Disord 20(5): 319-25.

Wang G.S., M.N. Kuyumcu-Martinez, et al. (2009). PKC inbibition ameliorates the cardiac phenotype in a mouse model of myotonic dystrophy type 1. J Clin Invest 119(12): 3797-806.

Wang L.C., K.Y. Chen, et al. (2011). Muscleblind participates in RNA toxicity of expanded CAG and CUG repeats in Caenorbabditis elegans. Cell Mol Life Sci 68(7): 1255-67.

Ward A J., M. Rimer, et al. (2010). CUGBP1 overexpression in mouse skeletal muscle reproduces features of myotonic dystrophy type 1. Hum Mol Genet 19(18): 3614-22.

Wheeler T.M., J.D. Lueck, et al. (2007). Correction of ClC-1 splicing eliminates chloride channelopathy and myotonia in mouse models of myotonic dystrophy. J Clin Invest 117(12): 3952-7.

Yadava R.S., C.D. Frenzel-McCardell, et al. (2008). RNA toxicity in myotonic muscular dystrophy induces NKX2-5 expression. Nat Genet 40(1): 61-8. 